\title{
KELIMPAHAN GASTROPODA DI PESISIR KECAMATAN RANGSANG, KABUPATEN KEPULAUAN MERANTI
}

\author{
Yeeri Badrun \\ Fakultas MIPA dan Kesehatan \\ Universitas Muhammadiyah Riau Tahun \\ Email: yeeri.badrun@umri.ac.id
}

\begin{abstract}
ABSTRAK
Penelitian ini bertujuan untuk mengetahui Kelimpahan Gastropoda yang ada di Vegetasi Mangrove Desa Topang, Kecamatan Rangsang, Kabupaten Kepulauan Meranti. Penelitian dilaksanakan dengan metode survei pada 4 stasiun penelitian. Hasil penelitian menunjukkan Kelimpahan rata-rata Gastropoda pada Stasiun I ditemukan sebanyak 12 $\mathrm{ind} / \mathrm{m}^{2}$, Stasiun II ditemukan sebanyak $8 \mathrm{ind} / \mathrm{m}^{2}$, Stasiun III ditemukan sebanyak $16 \mathrm{ind} / \mathrm{m}^{2}$, dan Stasiun IV ditemukan sebanyak $11 \mathrm{ind} / \mathrm{m}^{2}$.
\end{abstract}

Kata Kunci: Kelimpahan, Mangrove, Gastropoda

\section{PENDAHULUAN}

Salah satu wilayah pesisir di Provinsi Riau adalah Desa Topang yang terletak di Kecamatan Rangsang, Kabupaten Kepulauan Meranti, yang memiliki luas wilayah sekitar 29,13 km dengan jumlah penduduk 2.739 jiwa. Letak geografis desa ini di kelilingi laut dan banyak terdapat hutan mangrove di sepanjang pesisir pantai (Profil Desa Topang Tahun 2014). Menurut informasi yang didapatkan dari Kepala Desa setempat, di wilayah desa Topang belum pernah dilakukan penelitian tentang keberadaan gastropoda yang ada di mangrove.

Diharapkan penelitian ini dapat digunakan sebagai data dasar dan informasi tentang kelimpahan Gastropoda yang ada di vegetasi hutan mangrove Pesisir Pantai Desa Topang, diharapkan pula berguna dalam upaya mengelola sumberdaya hayati mangrove, Gastropoda dan organisme lainnya.

\section{METODOLOGI PENELITIAN}

Penelitian dilakukan pada Bulan Mei-Juni 2015 di Pesisir Pantai Desa Topang, Kecamatan Rangsang, Kabupaten Kepulauan Meranti, Provinsi Riau. Identifikasi Gastropoda dilaksanakan di Laboratorium Biologi FMIPA dan Kesehatan Universitas Muhammadiyah Riau.

Peralatan yang digunakan dalam penelitian adalah Higrometer, $\mathrm{pH}$ meter, Salinometer, Termometer air raksa, tali plastik, meteran gulung, gunting tanaman, pancang, kamera digital, dan botol/kantong sampel, cool box atau wadah penyimpanan sampel, dan alat tulis. Bahan penelitian adalah alkohol $70 \%$ dan formalin 40 $\%$ untuk pengawetan Gastropoda.

Metode yang digunakan dalam penelitian ini adalah metode survey, dimana ekosistem mangrove dan kelimpahan Gastropoda di Pesisir Pantai Desa Topang dijadikan sebagai lokasi pengamatan untuk memperoleh data primer. Penelitian dilakukan pada empat stasiun, pada setiap stasiun dibuat dua transek dengan jarak antara transek $50 \mathrm{~m}$. Pada masing-masing transek dibuat 5 plot pengamatan dengan ukuran $2 \mathrm{~m} \times 2$ $\mathrm{m}$ pengamatan Gastropoda. Pengambilan sampel Gastropoda pada masing-masing stasiun dilakukan satu kali pada hari yang berbeda saat air surut.

Pengambilan sampel Gastropoda dilakukan pada saat air surut. Sampel Gastropoda yang berada di atas substrat dan yang menempel pada akar mangrove yang berada di dalam sub plot 2 $\mathrm{m} \times 2 \mathrm{~m}$ diambil seluruhnya, sampel yang telah didapatkan dimasukkan ke dalam cool box dan diawetkan dengan Formalin $40 \%$ kemudian diidentifikasi berdasarkan Buku (Roberts et al., 1982).

Parameter kualitas lingkungan yang diukur adalah $\mathrm{pH}$ tanah, suhu tanah, salinitas perairan, suhu udara, dan kelembaban udara pengukuran dilakukan pada saat pengamatan pada masingmasing stasiun. 


\section{HASIL DAN PEMBAHASAN}

Gastropoda yang ditemukan pada hutan mangrove di Desa Topang adalah sebanyak 11 jenis yaitu, Acanthinucella sp, Chicoreus capucinus, Cerithidca cingulata, Cassidula lutescens, Cassidula mastelina, Cerithidea quadrata, Ellobium aurisjudae, Nerita funiculata, Neritina violacea, Thais sp, Telescopium telescopium.

Jumlah individu dan kelimpahan Gastropoda yang ditemukan pada setiap stasiun menunjukkan adanya perbedaan. Spesies yang banyak ditemukan yaitu adalah $C$. lutescens berjumlah yaitu 62 individu, sedangkan yang paling sedikit adalah $A$. sp, E. aurisjudae, C. mastelina, dan $N$. violacea masing-masingnya berjumlah 1, Kelimpahan rata-rata yang paling banyak ditemukan pada Stasiun III sebanyak $16 \mathrm{ind} / \mathrm{m}^{2}$, kelimpahan yang sedikit ditemukan pada Stasiun II sebanyak $8 \mathrm{ind} / \mathrm{m}^{2}$.

Tabel 4. Jumlah Individu dan Nilai Kelimpahan Gastropoda di Setiap Lokasi Penelitian

\begin{tabular}{|c|c|c|c|c|c|c|c|c|c|}
\hline \multirow{3}{*}{ Spesies } & \multicolumn{4}{|c|}{ 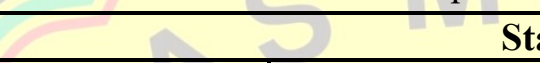 } & \multicolumn{4}{|c|}{ asiun } & \multirow{3}{*}{$\begin{array}{l}\text { Total } \\
\text { Ind }\end{array}$} \\
\hline & \multicolumn{2}{|r|}{ I } & \multicolumn{2}{|r|}{ II } & \multicolumn{2}{|c|}{ III } & \multicolumn{2}{|r|}{ IV } & \\
\hline & $\begin{array}{l}\text { Jlh } \\
\text { Ind }\end{array}$ & $\begin{array}{c}\mathbf{K} \\
\left(\operatorname{Ind} / \mathbf{m}^{2}\right)\end{array}$ & $\begin{array}{l}\text { Jlh } \\
\text { Ind }\end{array}$ & $\begin{array}{c}\mathbf{K} \\
\left(\mathbf{I n d} / \mathbf{m}^{2}\right)\end{array}$ & $\begin{array}{l}\text { Jlh } \\
\text { Ind }\end{array}$ & $\begin{array}{c}\mathrm{K} \\
\left(\mathrm{Ind} / \mathbf{m}^{2}\right)\end{array}$ & $\begin{array}{l}\text { Jlh } \\
\text { Ind }\end{array}$ & $\begin{array}{c}\text { K } \\
\left(\operatorname{Ind} / \mathbf{m}^{2}\right)\end{array}$ & \\
\hline A. $\mathrm{sp}$ & - & - & - & - & 1 & 0,025 & - & - & 1 \\
\hline C. $c$ & 6 & 0,15 & - & - & 8 & 0,2 & 4 & 0,1 & 18 \\
\hline C.ci & - & - & 3 & 0,075 & - & - & 3 & 0,07 & 6 \\
\hline C. 1 & 14 & 0,35 & 7 & 0,175 & 31 & 0,775 & 10 & 0,25 & 62 \\
\hline C. $\mathrm{m}$ & - & - & 1 & 0,025 & - & - & - & - & 1 \\
\hline C. $q$ & 18 & 0,45 & 6 & 0,15 & 10 & 0,25 & 15 & 0,375 & 49 \\
\hline E. a & - & - & - & - & - & - & 1 & 0,025 & 1 \\
\hline N.f & - & - & - & - & 3 & 0,075 & 2 & 0,25 & 5 \\
\hline N. v & - & - & - & - & - & - & 1 & 0,025 & 1 \\
\hline T. $\mathrm{sp}$ & 3 & 0,075 & 2 & 0,05 & 2 & 0,05 & 9 & 0,225 & 16 \\
\hline T.t & 5 & 0,125 & 19 & 0,457 & 9 & 0,225 & 3 & 0,075 & 36 \\
\hline Jumlah & 46 & 1,15 & 33 & 0,807 & 64 & 1,6 & 42 & 1,175 & 189 \\
\hline Jumlah Jenis & & 5 & & 6 & & 7 & & 9 & \\
\hline K Rtt (Ind/m2) & & 12 & & 8 & & 16 & & 11 & \\
\hline
\end{tabular}

Keterangan : A. $\mathrm{sp}=$ Acanthinucella $\mathrm{sp}, C . c=$ Chicoreus capucinus , $C$. ci=Cerithidea cingulata, $C$. $l=$ Cassidula lutescens, $C . m=$ Cassidula mastelina, $C . q=$ Cerithidea quadrata, E. $a=$ Ellobiumaurisjudae, $N . f=$ Nerita funiculata, $N . v=$ Neritina violacea, $T . \mathrm{sp}=$ Thais $\mathrm{sp}, T t=$ Telescopium telescopium.

\section{Parameter Kualitas Lingkungan}

Hasil pengukuran parameter kualitas lingkungan di Pesisir Pantai Desa Topang yaitu maliputi $\mathrm{pH}$ tanah, $\mathrm{pH}$ air, suhu tanah, suhu air, kelembaban, salinitas didapatkan bahwa hasil pengukuran parameter lingkungan dikawasan penelitian menunjukkan $\mathrm{pH}$ Tanah $6, \mathrm{pH}$ Air berkisar antara 6-7, Suhu Tanah berkisar antara $27{ }^{\circ} \mathrm{C}-30{ }^{\circ} \mathrm{C}$, Suhu Air berkisar antara $29^{\circ} \mathrm{C}$ $32^{\circ} \mathrm{C}$, Kelembaban berkisar antara $40 \%-45 \%$, Salinitas berkisar antar 21-22 \%o.

Tabel 5. Nilai Parameter Lingkungan Gastropoda pada Setiap Stasiun Penelitian

\begin{tabular}{|c|c|c|c|c|}
\hline Parameter & Stasiun I & Stasiun II & Stasiun III & Stasiun IV \\
\hline pH Tanah & 6 & 6 & 6 & 6 \\
\hline pH Air & 7 & 6 & 7 & 6 \\
\hline Suhu Tanah & $30^{\circ} \mathrm{C}$ & $27^{\circ} \mathrm{C}$ & $28^{\circ} \mathrm{C}$ & $30^{\circ} \mathrm{C}$ \\
\hline Suhu Air & $29^{\circ} \mathrm{C}$ & $29^{\circ} \mathrm{C}$ & $32^{\circ} \mathrm{C}$ & $29^{\circ} \mathrm{C}$ \\
\hline Kelembaban & $40 \%$ & $45 \%$ & $40 \%$ & $40 \%$ \\
\hline
\end{tabular}




\begin{tabular}{|c|c|c|c|c|}
\hline Parameter & Stasiun I & Stasiun II & Stasiun III & Stasiun IV \\
\hline Salinitas & $20 \% 0$ & $21 \% 0$ & $21 \% 0$ & $22 \% 0$ \\
\hline
\end{tabular}

\section{Pembahasan}

Kelimpahan rata-rata Gastropoda yang paling tinggi ditemukan pada Stasiun III sebesar $16 \mathrm{ind} / \mathrm{m}^{2}$, dan kelimpahan rata-rata yang terendah pada Stasiun II sebesar 8 ind $/ \mathrm{m}^{2}$. Kelimpahan Gastropoda ini diduga ada hubungannya dengan keanekaragaman mangrove pada masing-masing stasiun (Tabel 4.2). Indek Keanakaragaman Stasiun III paling tinggi dibandingkan stasiun lainnya sehingga menyediakan sumber makanan yang banyak bagi Gastropoda. Menurut Zamroni dan Rohyani (2008), serasah memberikan kontribusi besar terhadap detritus organik yang sangat penting sebagai sumber makanan bagi biota salah satunya adalah Gastropoda.

Rendahnya kelimpahan pada Stasiun II diduga pada Stasiun II yang sudah mulai tercemar dengan banyaknya aktifitas manusia menyebabkan menumpunya sampah-sampah pasar dan sisa-sisa minyak kapal disekitar pelabuhan yang terdapat di Stasiun II ini. Hal ini sesuai dengan pernyataan Vatria (2010), dari sekian banyak penyebab kerusakan lingkungan laut dan pesisir, pencemaran merupakan faktor yang paling penting. Hal ini disebabkan karena pencemaran tidak saja dapat merusak atau mematikan komponen biotik (hayati) perairan, tetapid apat pula membahayakan kesehatan atau bahkan mematikan manusia yang memanfaatkan biota atau perairan yang tercemar. Selain itu pencemaran juga dapat menurunkan nilai estetika perairan laut dan pesisir yang terkena pencemaran.

Hasil pengukuran $\mathrm{pH}$ air pada 4 stasiun penelitian di Desa Topang pada vegetasi mangrove didapatkan $\mathrm{pH}$ air berkisar yaitu 6-7. Menurut Michel (1994), umumnya Gastropoda yang hidup di ekosistem mangrove membutuhkan $\mathrm{pH}$ air antara 6-8,5 untuk kelengsungan hidup dan reproduksi.

Kisaran suhu air pada setiap stasiun pengamatan di Desa Topang memiliki kisaran suhu berbeda yaitu $29^{\circ} \mathrm{C}-32^{\circ} \mathrm{C}$. Menurut Jesus (2012), di Sub District Timor Leste menyatakan bahwa perbedaan kisaran suhu pada masingmasing stasiun penelitian lebih banyak disebabkan oleh faktor intensitas sinar matahari yang terpapar langsung dilingkungan mangrove karena suhu bergantung pada kerapatan mangrove. Pada stasiun pengamatan yang kerapatan mangrovenya jarang menyebabkan intensitas sinar matahari langsung menembus badan air dan menyebabkan suhu menjadi tinggi pada siang hari yaitu pada kisaran $30^{\circ} \mathrm{C}$.

Hasil pengukuran Kelembaban pada setiap stasiun penelitian di Desa Topang berbeda-beda yang berkisar antara 40\%-45\%. Zamroni dan Rohyani (2008), suhu dan kelembaban udara mempengaruhi jatuhan serasa mangrove, naiknya suhu udara akan menyebabkan menurunnya kelembaban udara.

Hasil pengukuran salinitas pada setiap stasiun penelitian di Desa Topang berbeda-beda yang berkisar antara 21\%o-22\%o. Menurut Hartoni dan Andi (2013), Kisaran nilai salinitas untuk pertumbuhan optimal mangrove adalah 10\%o-30\%o. Nilai salinitas dipengaruhi kondisi muara yang bervariasi dan cenderung rendah saat air laut surut karena mendapatkan pengaruh aliran air tawar dan cenderung tinggi saat air laut pasang karena mendapatkan pengaruh air laut.

\section{KESIMPULAN DAN SARAN}

\section{Kesimpulan}

Gastropoda yang ditemukan adalah: Acanthinucella sp, Chicoreus capucinus, Cerithidea cingulata, Cassidula lutescens, Cassidula mastelina, Cerithidea quadrata, Ellobium aurisjudae, Nerita funiculata, Neritina violacea, Thais sp, Telescopium telescopium. Spesies yang banyak ditemukan yaitu adalah Cassidula lutescens berjumlah yaitu 62, sedangkan yang paling sedikit adalah Acanthinucella sp, E. aurisjudae, C. mastelina, dan Neritina violacea masing-masingnya berjumlah 1, Kelimpahan rata-rata Gastropoda pada Stasiun I ditemukan sebanyak $12 \mathrm{ind} / \mathrm{m}^{2}$ Stasiun II ditemukan sebanyak $8 \mathrm{ind} / \mathrm{m}^{2}$, Stasiun 
III ditemukan sebanyak $16 \mathrm{ind} / \mathrm{m}^{2}$, dan Stasiun IV ditemukan sebanyak $11 \mathrm{ind} / \mathrm{m}^{2}$.

\section{Saran}

Disarankan dalam penelitian selanjutnya dilakukan penelitian tentang vegetasi mangrove di lokasi penelitian yang sama dengan rentang waktu tertentu serta mengetahui hubungan Gastropoda dengan jenis tumbuhan mangrove.

\section{Ucapan Terimakasih}

Penulis mengucapkan terimakasih kepada Ibu Novia Gesriantuti yang telah membantu melakukan analisis, evaluasi dan koreksi pelaksanaan penelitian ini. Ucapan terimakasih juga disampaikan pada Nurmeli Pebriani yang telah membantu pelaksanaan survai dan pengambilan sampel di lapangan dan analisis di laboratorium.

\section{DAFTAR PUSTAKA}

Campbell, N, A. Reece, B, J. dan Mitchell, G, L. 1999. Biologi edisi ke lima jilid dua. Edisi Terjemahan. Erlangga.

Dahuri, R. 2003. Keanekaragaman Hayati Laut. Gramedia Pustaka Utama. Jakarta.

Haris, M. 2013 Struktur Komunitas dan Komposisi Vegetasi Mangrove di Kabupaten Indragiri Hilir Provinsi Riau. Skripsi tidak diterbitkan. Fakultas MIPA dan Kesehatan Universitas Muhammadiyah Riau. Pekanbaru.

Hendri, F. 2014. Hubungan Kerapatan Mangrove Dengan Kelimpahan Gastropoda di Desa Sungai Alam Kecamatan Bengkalis Kabupaten Bengkalis Provinsi Riau. Skripsi tidak diterbitkan. Fakultas Perikanan dan Ilmu Kelautan Universitas Riau. Pekanbaru.

Heddy, S. 2012. Metode Analisis Vegetasi Dan Komunitas. Penerbit PT Raja Grafindo Persada. Jakarta.

Hartoni, dan A, Agussalim. 2013. Komposisi dan Kelimpahan Moluska (Gastropoda dan Bivalvia) di Ekosistem Mangrove Muara Sungai Musi Kabupaten Banyu Asin Provinsi Sumatera Selatan. Maspari
Journal Volume 5, Nomor 1, Januari 2013: 6-15

Indriyanto. 2012. Ekologi Hutan. Bumi Aksara. Jakarta.

Islahati. 2013 Keanekaragaman Vegetasi Mangrove di Pantai Solop Desa Pulau Cawan Kecamatan Mandah Kabupaten Indragiri Hilir Propinsi Riau. Skripsi tidak diterbitkan. Fakultas MIPA dan Kesehatan Universitas Muhammadiyah Riau. Pekanbaru.

Informasi Laporan Penyelenggaraan Pemerintahan Daerah (ILPD) Kabupaten Kepulauan Meranti Tahun 2013.

Jesus, A. D. 2012. Kondisi Ekosistim Mangrove di Sub District Liquisa Timor-Leste. Pascasarjana Fakultas Perikanan dan Ilmu Kelautan Universitas Brawijaya. Malang. Depik, 1(3): 136-143 Desember 2012 ISSN 2089-7790.

Kelompok Kerja Mangrove Tingkat Nasional. 2013. Strategi Nasional Pengelolaan Ekosistem Mangrove Indonesia.

Michael, P. 1994. Metode Ekologi Untuk Penyelidikan Ladang Dan Laboratorium. Edisi Terjemahan. UI-PRESS. Jakarta.

Nontji, A. 2007. Laut Nusantara. Djambatan, Jakarta.

Noor, Y, R, Khazali, M, dan Suryadiputra, I N, N 2006. Panduan Pengenalan Mangrove di Indonesia. Wetlands Internasional Indonesia Programme. Bogor.

Onrizal. 2008. Panduan Pengenalan dan Analisis Vegetasi Hutan Mangrove. Deperteman Kehutanan. Fakultas Pertanian. Universitas Sumatra Utara.

Pramudji. 2001. Ekosistem Hutan Mangrove Dan Peranannya Sebagai Habitat Berbagai Fauna Aquatik. Jurnal Oseana. Volume XXVI, Nomor 4, 2001:13 - 23

Profil Desa Topang Tahun, 2014. Kepala Desa. Desa Topang.

Rau, A, R. Kusen, D, J. Carolus P, P. 2013. Struktur Komunitas Moluska Di Vegetasi Mangrove Desa Kulu. Kecamatan Wori, Kabupaten Minahasa Utara. Jurnal Pesisir Dan Laut Tropis. Vulome 2 nomor 1 tahun 2013. 
Roberts, D, Soemodihardjo, S, dan W, Kastoro. 1982. Shallow water Marine Molluscs Of Nort-West Java. Lembaga Oseoanologi Nasional. Lembaga Ilmu Pengetahuan Indonesia. Jakarta.

Rommimohtarto, K dan Juwana, S. 2009. Biologi Laut. Djambatan Jakarta.

Saparinto, C. 2007. Pendayagunaan Ekosistem Mangrove. Penerbit Dahara Prize. Semarang.

Silaen, I, F, Boedi, H, dan Mustofa, N, S. 2013. Distribusi Dan Kelimpahan Gastropoda Pada Hutan Mangrove Teluk Awur Jepara. Journal of Management Of Aquatic Resources Volume 2, Nomor 3, Tahun 2013, Halaman 93-103.

Steenis, V. C. G. G. J., Bloembergen, S., dan
Eyma, P, J. 2008. Flora. Edisi terjemahan. Penerbit PT Pradnya Paramita. Jakarta.

Suwandhi, I. dan Heryandi, C. 2007. Hutan Bakau Manfaat Bagi Lingkungan Dan Kehidupan Manusia. Penerbit PT Sinergi Pustaka Indonesia. Bandung.

Vatria, B. 2010. Berbagai Kegiatan Manusia Yang Dapat Menyebabkan Terjadinya Degradasi Ekosistem Pantai Serta Dampak Yang Ditimbulkannya. Jurnal Belian Vol. 9 No. 1 Jan. 2010: 47 - 54.

Zamroni, Y. dan I, S, Rohyani. 2008. Produksi Serasah Hutan Mangrove di Perairan Pantai Teluk Sepi, Lombok Barat. Jurnal Biodiversitas Volum 9 (4) : Hal 284 287. 